\title{
Proposal of coeliac disease management during Covid-19 pandemia
}

\author{
Matteo Piciucchi ${ }^{*}$, Alice Rossi ${ }^{1}$, Alissa Satriano ${ }^{2}$ and Raffaele Manta ${ }^{3}$ \\ ${ }^{1}$ Digestive Endoscopy Unit, Santa Maria Hospital of Orvieto (TR), Italy \\ ${ }^{2}$ Nutriton Department, General Hospital of Perugia (PG), Italy \\ ${ }^{3}$ Gastroenterology and Digestive Endoscopy, General Hospital of Perugia (PG), Italy
}

\section{Dear Editor,}

Since January 2020 novel 2019 betacoronavirus, also called Covid-19, greatly spread throughout the world, exceeding 4000000 infected cases [1]. Covid-19 related disease shown highly variable clinical course which can range from simple infection to severe pneumonia and multiorgan failure [1,2]. Some risk factors for severe Covid-19 course were identified, but specific target treatments for infection are still lacking, so that mortality rate for Covid-19 still remains high especially in patients with preexistent - cardiovascular in particular - diseases [1,2].

Taking this into account, accurate prevention of contagion is the main strategy to contain mortality and infection's diffusion [3]. Italy was one of the most involved countries in Covid-19 pandemic and extraordinary several social restrictions have been imposed. In this view, hospital facilities in epidemic areas have to be considered as high-risk site to contract infection. Regardless of the field of medical work, the new scenario of Covid-19 pandemic therefore requires radical changes in clinical activities. Concerning the gastroenterologists, it is crucial to avoid unnecessary - or even inappropriate - hospital admissions, endoscopic examinations and outpatient visits as strongly suggests from Italian Societies of Gastroenterology and Endoscopy [4,5].

In particular, management of celiac disease is mainly based on periodic outpatient checks who currently need a telemedicine remote approach.

Based on current studies, celiac patients do not seems to have increased risk for Covid-19 infection or severe related disease even if hyposplenism and higher risk of bacterial pneumonia may be present especially when celiac disease is associated with other autoimmune disorders [6].

The majority of coeliac patients in follow-up in hospital referral centers are long-term disease subjects in good general status without clinical complication [7]. They generally undergo yearly clinical control and monitoring of biochemical nutritional parameters and of anti-transglutaminase IgA levels [6]. In this group of patients, visit by phone should be preferred to contact in person and on the absence of biochemical alterations or clinical symptoms detectable during accurate interview, they may be safely directly addressed to next annual check. Routine endoscopic/histological revaluation scheduled before Covid-19 pandemic must be deferred until the end of emergency, except in highly suspected cases of celiac disease refractory to diet in which histological diagnosis is mandatory to establish urgent medical treatment [8].
In highly suspected celiac patients with elevated antitransglutaminase, diagnostic endoscopy should not be delayed to early start free gluten diet and avoid the onset or worsening of malabsorption related complication.

In newly diagnosed celiac patients, clinical counseling and dietician support are crucial to correct approach free gluten diet, as is an accurate evaluation of physical status and symptoms in order to assess their improvement after diet starting $[7,8]$. In our opinion, in these cases the need for direct contact with the doctor should be carefully evaluated on "case by case" basis. Especially in high-risk patients for severe Covid-19 course - older and cardiovascular patients as well as obese and immunosuppressed subjects - clinical remote approach should be ever attempt. Italian Ministry of Health strongly recommends this approach and free official informatics applications were released to perform visual remote visits using phone, tablet or PC [9]. Telemedicine obviously requires compliance that patients not always are able to assure due to cultural/economical barrier.

Traditional outpatient visits - observing opportune hygienic precaution - must be guaranteed in this subgroup of patients or in presence of celiac disease related complications requiring more complex medical treatment such as severe anemia or refractory coeliac disease. Even if specific studies or guidelines have not been released, in refractory celiac patients without Covid-19 infection managed in epidemic areas, immunosuppressive treatment should not be delayed - or early stopped - like to what recommended for oncological and autoimmune diseases [10].

In conclusion, we wanted to focus attention on the need to remodel celiac disease management during the Covid-19 pandemic. Even if in Italy infection peak seems to be passed, while waiting for vaccine and/ or effective therapy, it will be necessary to maintain these new medical approaches to cohabit with the virus in the post emergency long-term course of Covid-19 pandemic.

\section{Conflict of interest}

No author has conflicts of interest to declare.

${ }^{\star}$ Correspondence to: Matteo Piciucchi, Santa Maria Hospital of Orvieto, Località Ciconia, 05018 Orvieto (TR), Italy, E-mail: matteo.piciucchi@uslumbria2.it

Key words: celiac disease, covid-19 pandemic, telemedicine

Received: June 01, 2020; Accepted: June 12, 2020; Published: June 17, 2020 


\section{References}

1. Rodriguez-Morales AJ, Cardona-Ospina JA, Gutiérrez-Ocampo E, Villamizar-Peña R, Holguin-Rivera Y, et al. (2020) Clinical, laboratory and imaging features of COVID-19: A systematic review and meta-analysis. Travel Med Infect Dis. 101623. [Crossref]

2. Zheng Z, Peng F, Xu B, Zhao J, Liu H, et al. (2020) Risk factors of critical \& morta COVID-19 cases: A systematic literature review and meta-analysis. $J$ Infect pp: 30234 30236 .

3. Nussbaumer-Streit B, Mayr V, Dobrescu AI, Chapman A, Persad E, et al. (2020) Quarantine alone or in combination with other public health measures to control COVID-19: a rapid review. Cochrane Database Syst Rev 4: CD013574. [Crossref]

4. Gastroenterology and Digestive Endoscopy (Phase II Covid-19 Emergency): Parte 1- Digestive Endoscopy Activities. Italian Federation of Digestive Diseases Societies. [Available at] https://fismad.it/wp-content/uploads/2020/04/FISMADCovid19Fase2 Parte1ENDO.pdf.

5. Gastroenterology during COVID-19 pandemic (2020) FISMAD recommendations. Italian Federation of Digestive Diseases Societies. [Available at] https://fismad.it/wpcontent/uploads/2020/04/FISMAD_COVID19_REV01_eng.pdf.
6. Simons M, Scott-Sheldon LA Simons M, Scott-Sheldon LAJ, Risech Neyman Y, et al. (2018) Disease and Increased Risk of Pneumococcal Infection: A Systematic Review and Meta-Analysis. Am J Med. 131: 83-89. [Crossref]

7. Alberto Rubio-Tapia, Ivor D Hill, Ciarán P Kelly, Audrey H Calderwood, Joseph A Murray (2013) ACG Clinical Guidelines: Diagnosis and Management of Celiac Disease. Am J Gastroenterol 108: 656-677. [Crossref]

8. Ludvigsson JF, Bai JC, Biagi F, Card TR, Ciacci C, et al. (2014) Disease Guidelines Development Group; British Society of Gastroenterology. Diagnosis and management of adult coeliac disease: guidelines from the British Society of Gastroenterology. Gut 63: 1210-1228. [Crossref]

9. Gabbrielli F, Bertinato L, De Filippis G, Bonomini M, Cipolla M (2020) Italian Institute of Health (ISS). Interim provisions on telemedicine healthcare services during COVID-19 health emergency. p 29.

10. Sarzi-Puttini P, Marotto D, Antivalle M, Salaffi F, Atzeni F, et al. (2020) How to handle patients with autoimmune rheumatic and inflammatory bowel diseases in the COVID-19 era: An expert opinion. Autoimmun Rev 5: 102574. [Crossref]

Copyright: $@ 2020$ Piciucchi M. This is an open-access article distributed under the terms of the Creative Commons Attribution License, which permits unrestricted use, distribution, and reproduction in any medium, provided the original author and source are credited. 